\title{
REPERE ÎN ABORDAREA DESIGNULUI METODOLOGIC AL CERCETĂRII Loredana MANASIA
}

Abstract:

This article focuses on developing research design in educational sciences research field. Firstly, it will be important to dissociate between three major aims of the research: exploration, description and explanation. Setting the goal of the research will conduct to the next step, meaning research conceptualization. Based on the research framework, the research strategy is formulated, unfolding other decisions to make regarding research methods. At the end, the article offers the answer of targeting research population and applying adequate sampling methods.

Key words: research design, rearch methods, variables, research sample

\section{Introducere}

Ştiinţa este indubitabil o acţiune dedicată descoperirii (Babbie, 2010), precedată de un amplu proces de căutare. Babbie (2010) ne asigură că un ansamblu semnificativ din particularitătile activitătii de

1 Loredana MANASIA este doctorandã a Şcolii Doctorale de Psihologie și Ștrinnţele Educaţiei, Universilatea din București. 
cercetare face parte din repertoriul nostru încă din copilărie. Nu vom nega că multiple descoperiri se produc în cotidianul imediat al fiecăruia dintre noi fără a avea totuși un impact la nivelul științei. Deși în plan simbolic sau metaforic orice om este un cercetător, ancorarea in dimensiunea procedurală ne indică a fi necesară o segmentare între Experți și Consumatorii de Poveşti.

Cercetătorii Experți sunt cei care pot să ofere răspunsul întrebărilor de ce şi cum poate fi analizat un fenomen, pot proiecta, in fapt, un design al unei cercetări ştiinţifice. Consumatorii de Poveşti sunt exponenţi ai cunoaşterii comune. Demersul pe care îl propunem în continuare face referire la cercetătorii experți și la modul în care pot fi operaţionalizate întrebările de ce şi cum, care încadrează designul metodologic al unei cercetări ştiinţifice. Exemplul pe care îl vom supune analizei este proiectul de cercetare propus pentru elaborarea tezei de doctorat cu tema "Metacogniţia şi comunitătile de invătare".

\section{Explorare- Deseriere-Explicare}

Cercetările conduse în domeniul ştiinţelor sociale, în general, dar și la nivelul ştiințelor educaţiei pot să îşi propună trei categorii de finalităti de rang major: explorarea unui fenomen, descrierea acestuia sau explicarea condiţiilor în care acesta se produce și a factorilor care îl alimentează. Acest continuum al finalităților majore ale cercetării nu se regăseşte în mod obligatoriu în fiecare studiu realizat. Interesele cercetătorului, condiţiile de colectare a datelor, timpul necesar analizei şi interpretării, utilitatea demersului de cercetare, dar şi raţiuni financiare 
pot fi factori care determină orientarea către o categorie specifică de finalităţi. În continuarea acestưi demers ne propunem 0 abordare schematică a cercetării exploratorii, descriptive şi explicative, scopul fiind acela de a le integra în ceea ce vom numi cadrul general de structurare a investigaţiei, modelul de cercetare.

\subsection{Cercetarea exploratorie}

Există un corp de cercetări conduse pentru a explora un anumit subiect sau o problemă de cercetare, adică pentru a începe familiarizarea cercetătorului cu aceasta (Babbie, 2010). O abordare exploratorie este preferată în contextul în care cercetătorul analizează un aspect nou sau când problema de cercetare in ansamblu prezintã un grad ridicat de noutate.

Paradigma cu care se relaţioneză acest tip de cercetare este cea calitativă, pentru că necesită o abrodare în profunzime care să atingă atitudini, motivații sau euristici specifice indivizilor. La nivel de metode de cercetare, pot fi utilizate focus-grupuri, diade, interviuri in profunzime, jurnale, biografii sau alte elemente metodologice care constituie apanajul cercetării calitative.

Pertinenţa şi utilitatea unei unui demers investigaţional exploratoriu sunt motivate de nevoia de satisfacere a curiozității cercetătorului, de testarea fezabilității derulării unei cercetări mai ample şi de dezvoltarea unor instrumente fidele pentru un studiu realizat ulterior. 
Opţiunea cercetătorului pentru o cercetare de tip exploratoriu trebuie să aibă în vedere și o serie de neajunsuri care pot evolua către dezavantaje. Rezultatele unei astfel de cercetări nu pot fi generalizate şi, in cele mai multe dintre cazuri, au valoare orientativă. Eşantionul pe care este realizată această cercetare este de tip teoretic, fapt care corelează cu reprezentativitatea unităţilor de analiză cuprinse în eșantion. Şi, nu în ultimul rând, dacă demersul exploratoriu este integrat unei microcercetări, cercetătorul va fi interesat şi de aspectul cronofag, mai ales atunci când bugetul de timp nu este destul de generos.

\subsection{Cercetarea descriptivă}

Un scop major al multor cercetări ştiinţifice din domeniul ştiinţelor educaţiei este descrierea fenomenelor sau situaţiilor cu care cercetătorul vine în contact. Observaţia precede descrierea. Prin comparație cu cercetarea exploratorie care este relaționată cu paradigma calitativă, în cazul cercetării descriptive putem constata o dublă orientare paradigmatică atât calitativă, cât şi cantitativă. În acest context, putem vorbi de abordări etnografice, dar şi de cercetări descriptive care apelează la ancheta pe bază de chestionar, de exemplu. În cele mai multe dintre cazuri, cercetarea descripritvă precede studiile explicative, atunci când cercetătorul doreşte să răspundă şi întrebării de ce (are loc acest fenomen). 


\subsection{Cercetarea explicativă}

Cel de-a treia finalitate a cercetării ştiințifice in ştiinţele educaţiei vizează explicarea fenomenelor. Atât cercetarea exploratorie, cât şi cercetarea descriptivă răspund unor întrebări circumstanţiale pe care cercetătorul (şi) le poate adresa. Cercetarea explicativă este orientată către cauzalități şi corelații care se pot stabilii intre diferite fenomene.

\section{Etapa de conceptualizare a designului cercetării 3.1. Modelul de cercetare}

Cercetarea la care am făcut referire in debutul articolului, parte a proiectului Metacognitia şi comunilătile de invătare, este dezvoltată predominant pe o abordare descriptivă, hibridată în unele etape ale cercetārii cu abordări explicative. Pornind de la această orientare, am elaborat un model al cercetării care schematizează derularea logică a studiului (Fig. 1).

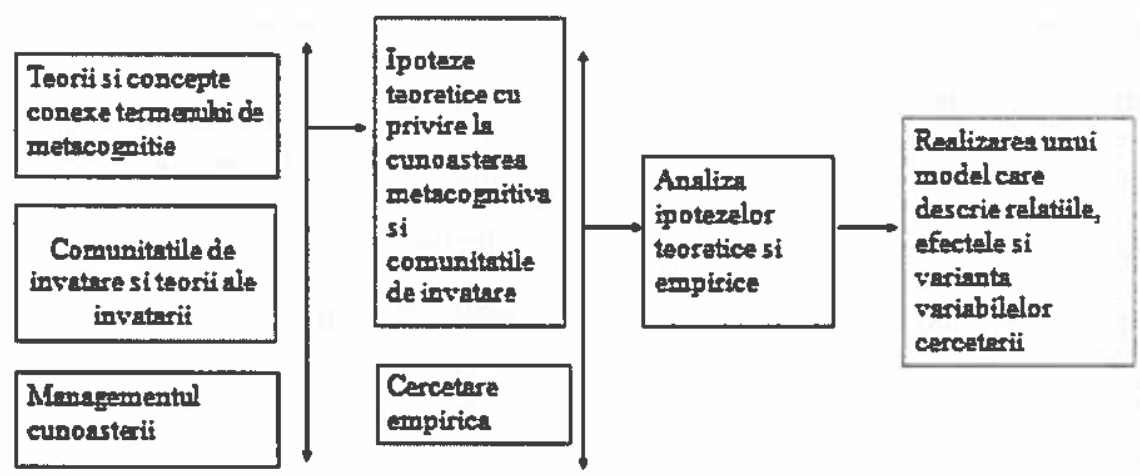

Fig. 1 . Modelul cercetării (conf. Verschuren şi Dorewaard, 2010) 
Modelul cercetării este o reprezentare iconică în care se stabileşte o relaţie de ordin logic şi cronologic intre elementele structurale ale cercetării. Intrările modelului (Verschuren şi Dorewaard, 2010) sunt delimitate de cadrul conceptual și teoretic al cercetării, realizând o clarificare a paradigmei ştiinţifice care fundamentează perspectiva teoretică şi abordarea metodologică a cercetării (Crotty, 1998).

Modelul de cercetare pentru care am optat in proiectarea acestui studiu descrie următoarele elemente: o analiză a literaturii de specialitate în ceea ce priveşte metacogniţia şi cunoaşterea metacognitivă, învăţarea socială şi comunitățile de învățare, relația dintre comunităţile de învățare şi nivelul de cunoaştere metacognitivă, efectele acestora asupra performanţei în rezolvarea de sarcini cognitive. Rezultatele acestei sinteze sunt testate la nivelul unei comunităti de invăţare formate din elevi adolescenţi cu performanțe şcolare scăzute și ridicate, urmate de rafinarea în cadrul unor interviuri în profunzime cu profesori. Informația astfel filtrată este confruntată cu cadrul teoretic şi va contribui la testarea ipotezelor de cercetare enunțate pentru acest studiu.

Crotty (1998) afirmă că în structurarea unei investigaţii ştiințifice, cercetătorul trebuie să răspundă unor întrebări cu rol de clarificare şi organizare:

- Ce paradigmă sau teorie a cunoaşterii fundamentează perspectiva teoretică şi abordarea metodologică a cercetării?

- Ce tip de cercetare va fi preferat?

- Ce strategie de cercetare leagă problema de cercetare de rezultatele cercetării (cercetare exploratorie, anchetă pe bază de interviu, etnografie etc.)? 
- Care sunt tehnicile și instrumentele de cercetare la care se va face apel în contextul cercetării propuse?

Relativ la modelul de cercetare prezentat, incadrarea paradigmatică și stabilirea tipului de cercetare corespund etapei de conceptualizare, care se referă la semnificaţia conceptelor şi a variabilelor de studiat. Interesul cercetătorului asupra variabilelor porneşte de la specificul cercetării în ştiințele educaţiei, şi anume acela de a analiza clase şi tipuri de indivizi (elevi, profesori, părinţi, manager educaţionali etc.). Comportamentul acestora intr-un anumit context este funcţie a unor grapări logice de atribute, pe care le numim variabile ale cercetării.

\subsection{Limbajul variabilelor}

Relaţia dintre atribute şi variabile formeză esenţa descrierii şi a explicaţiei în știinţă (Babbie, 2010). În exemplul prezentat, strategiile şi metodele de instruire metacognitivã şi colaborativă reprezintã variabilele pe care le vom introduce într-un context de învăţare pentu a observa efectele asupra performaţei în realizarea unor sarcini de natură cognitivă şi asupra nivelului de cunoaștere metacognitivă. Strategiile şi metodele de instruire sunt un dat, acestea nefiind problematizate în cadrul analizei. Asumăm că aceste variabile rămân constante pe parcursul cercetării, motiv pentru care le vom numi variabile independente. Se presupune că variabilele independente le determină pe cele dependente, adicã acele variabile ale căror valori variază ca urmare a acțiunii variabilelor independente. În exemplul nostru, performanța in realizarea sarcinilor 
cognitive şi nivelul de cunoaştere metacognitivă sunt exemple de variabile dependente.

Influența variabilelor independente nu este de tip determinist direct. Există factori care pot media influența variabilelor independente. în contextul cercetării prezentate, performanța şcolară ridicată şi scăzută sunt astfel de factori, pe care $\mathrm{i}$-am numit variabile intermediare.

Conform abordării plurinivelare a lui Crotty (1998), vom continua demersul de prezentare a fazelor designului cercetării prin detalierea aspectelor legate de tipul şi strategia de cercetare, privită ca ansamblu coerent de metode, tehnici, instrumente și procedee de cercetare, aflate într-o relaţie de interdependenţă cu populaţia şi eşantionul studiului.

\subsection{Tipul cercetării}

Verschuren şi Dorewaard (2010) disociază între doua tipuri majore de studii, în funcţie de finalitățile de rang mediu pe care şi le propun: studii orientate teoretic şi studii orientate practic. Cercetările teoretice sunt orientate către dezvoltarea sau testarea unor teorii, iar studiile practice, pe dezvoltarea, testarea şî evaluarea unor solutii pentru probleme practice.

Cercetarea pe care am prezentat-o spre analiză, Metacognitia şi comunitătile de învătare, poate fi definită, la un nivel primar de abordare, ca un studiu practic, menit să realizeze diagnoza unei stări de fapt şi monitorizarea evoluției unor indicatori metacognitiv cu rol semnificativ în învățare. Obiectivul central al lucrării este investigarea efectelor cunoaşterii metacognitive şi ale învăţării colaborative asupra performanţelor in rezolvarea sarcinilor cognitive. 
Dezvoltarea acestui studiu are la bază o abordare realistă (Pawson şi Tilley, 1997). O astfel de metodă asumă că rezultatele obţinute în urma unui studiu realist sunt aplicabile doar intr-un context specific şi în anumite condiții în care cercetarea s-a desfaş̧urat. $\mathrm{Cu}$ alte cuvinte, se recomandă prudență în generalizarea rezultatelor. Contextul în care se derulează cercetarea limitează posibilitatea generalizării rezultatelor în absența unui context similar de reproducere a cercetării.

\section{Strategia de cercetare}

În general, putem disocia între două tipuri majore de strategii de cercetare: cercetarea cantitativă şi cercetarea calitativă. Strategiile de cercetare calitativă au ca principali referali sensuri, concepte, definiţii, caracteristici, metafore simboluri şi descrieri ale obiectelor şi fenomenelor. Strategiile cantitative fac referire la aspecte măsurabile, cuantificabile ale obiectelor şi fenomenelor (Berg, 2004). Vom exprima preferința pentru stabilirea unui raport de complementaritate între cele două strategii, non-exclusiv, rezultând, astfel, abordarile mixte sau hibrid. Dezbaterile pe care le-a suscitat preferința pentru o strategie sau cealaltã sunt însă departe de a fi închise. Întrebarea recurentă vizează superioritatea abordării cantitative în detrimental celei calitative sau invers. În acord cu Miles şi Huberman (1994), vom argumenta că ambele abordări pot avea atât avantaje, cât şi dezavantaje.

Abordarea metodologică a studiului Metacognitia şi comunităţile de învătare este inductivă, operaţionalizată prin metode cantitative (ancheta pe bază de chestionar) şi calitative (etnografii şi netnografii, 
tehnica jurnalului, metoda reflectivă, eseul, observatia, interviul şi focus-grupul, grupuri T, analiza documentelor curriculare, studiul de caz) utilizate pentru a testa ipotezele formulate. Studiul va investiga efectele învătarii colaborative şi ale cunoaşterii metacognitive inserate într-un concept dedicate de arhitectură de învătare la nivelul rezolvării sarcinilor cognitive.

Strategia de cercetare este de tip hibrid, cantitativă şi calitativă, fiind incluse şi elemente de etnografie. Plaja largă de metode pe care le propunem pentru cercetarea la care am făcut referire ne va permite o măsurare fidelă a diferiţilor indicatori pe care $\mathrm{i}$-am stabilit în cadrul proiectului, oferindu-ne avantajele fiecăreia dintre aceste metode. Astfel, măsurarea nivelului metacognitiv va fi realizată printr-un chestionar autoadministrat, dar pentru investigarea conşstientizării strategiilor metacognitive vom prefera o abordare reflectivă, bazată pe metoda jurnalului.

Decizia privind conceptele de studiat şi metodele prin care se va realize acest lucru este succedată de etapa de operaţionalizare, legată intim de designul instrumentelor de cercetare. Acest aspect nu face obiectul acestui articol, astfel vom continua prin prezentarea unor aspect esanţiale legate de populaţia studiată şi selecția eşantionului.

\section{Populația şi eşantionul cercetării}

Pe lânga rafinarea conceptuală şi decizia asupra metodelor care vor fi utilizate, cercetătorul este responsabil şi de stabilirea populaţiei de investigat. Populaţia unui studiu este acel grup (de obiecei de oameni) 
despre care dorim să tragem concluzii (Babbie, 2010). Indiferent care este populaţia pe care o adresează studiul, este, indubitabil, imposibil să investigăm fiecare element al populaţiei. Studiul nostru îşi propune să investigheze elevi cu vârste între 16-18 ani şi profesori din învăţământul liceal, reyidenţi în mediul urban şi rural. În 2009, populația elevilor de liceu era constituită din 784361 de persoane, număr copleşitor care ne convinge fără a fi nevoie de alte argumente că nu vom putea investiga toată această populație, la care se adaugă şi cea a profesorilor. În acest moment al structurării investigaţiei intervine eşantionarea. Deciziile despre populație și eșantionare sunt legate de deciziile despre metoda de cercetare utilizată.

În exemplul nostru, şcolile în care învață elevii vor fi selectate pe criterii de convenienţă. Clasele de elevi în care se va implementa modelul de învăţare colaborativă cu strategii metacognitive vor fi selectate aleator. Elevii incluşi în eşantion vor avea un nivel socio-economic similar, dar performanţe şcolare diferite. Metoda de selecţie a elevilor face referire la o eşantionare simplă aleatoare. Dimensiunea finală a eşantionului de elevi: 1200 de subiecți, având caracteristicile sociodemografice și psihografice expuse mai sus.

Eşantionul de profesori va include cadre didactice titulare, la filiera teoretică, vocaţională şi tehnologică, cu minimum 5 ani de experienţă în invăţământ. Eşantionarea se va realiza prin conveniență. Dimensiunea finală a eşantionului de profesori: 400 de subiecţi.

În funcție de scopul anterior stabilit al cercetării, cercetătorul va ști dacă se impune selecţia unui eşantion probabilistic sau 
nonprobabilistic şi care este dimensiunea optimă a acestuja. Dimensiunea eşantionului corelează cu caracteristica de reprezentativitate a acestuia.

Etapa de design a cercetării este urmată de colectarea datelor, de procesarea preliminară a acestora pentru analiză și interpretare, etape pe care nu le vom aborda in acest material.

\section{Concluzii}

Aşa cum aratã acestă abordare de ansamblu, conceperea cercetării implică un set de decizii privitoare la problema de cercetare, subiectul care urmează a fi studiat, populạ̦ia analizată, metoda utilizată și finalitatea pe care o serveşte cercetarea.

Perspectivele de abordare a unui subiect de cercetare nu sunt neapărat nelimitate, dar suportă o combinatorică in care interesul, imaginaţia, experienţa, preferințele paradigmatice şi teoretice ale cercetătorului concură la realizarea unei abordări inedite.

În elaborarea unui proiect de cercetare, este necesară și o abordare reflectivă venită din partea cercetătorului. Acesta va trebui să identifice interesele personale in relaţie cu subiectul studiat, resursele de care dispune, dar şi abilităţile cu care poate instrumenta respective cercetare. Etapa de conceptualizare a cercetării joacă un rol important, daca nu definitoriu. Fundamentarea teoretică, stabilirea relaţiilor conceptuale sunt esenţiale în procesul de identificare a variabilelor şi de operaţionalizare a acestora la nivelul instrumentelor de cercetare. Odată cristalizate aceste aspecte putem avansa către definirea cadrului metodologic al cercetării - 
metoda sau metodele cele mai adecvate. Mixul de metode poate fi o alternativă productivă pentru datele colectate în cadrul cercetării.

Aceste etape ale structurării investigației nu se produc independent una de cealaltă, ci sunt interajustabile. Acesta este şi cazul alegerii populaţiei şi a metodei de eşationare. În funcţie de finalităţile majore şi intermediare ale cercetării, vom ştii care este populaţia care poate oferi răspuns subiectului investigat şi cum poate fi selectat eşantionul care urmează a fi investigat.

Vom concluziona spunând că realizarea designului unei cercetări suportă o abordare pesonalizată, care lasă loc de abordări noi pe o structură algoritmică.

\section{Referințe bibliografice}

1. Babbie, E. (2010). Practica cercetării sociale. Iaşi: Polirom.

2. Berg, B. (2004). Qualitative Research Methods for the social sciences. Boston: Pearson Education Inc.

3. Creswell, J. (2003). Research Design. Qualitative, Quantitative and Mixed Methods. Londra: SAGE Publications.

4. Crotty, M. (1998). The Foundation of Social Research. Meaning and perspective in the research process. Londra: SAGE Publications.

5. Da Vaus, D. (2001). Research design in social research. Londra: SAGE Publications.

6. Kvale, S. (1996). Interviews - An Introduction to Qualitative Research Interviewing. Londra: Sage Publications.

7. Miles, M. şi Huberman, A.M. (1994). Qualitative Data Analysis: An Expanded Sourcebook. . Londra: Sage Publications. 
8. Pawson, R. şi Tilley, N. (1997). Realistic Evaluation. Londra: SAGE Publications.

9. Verschuren, P. şi Doorewaard, H. (2010. Designing a research project. Amserdam: Eleven International Publishing. 